\title{
El territorio relevado, el territorio disputado. Apuntes sobre la implementación de Ley nacional 26.160 en Río Negro, Argentina ${ }^{1}$
}

\author{
Lorena Cañuqueo ${ }^{2}$
}

\begin{abstract}
RESUMEN
En noviembre de 2006, el Congreso Nacional argentino sancionó la Ley de Emergencia de la Propiedad Comunitaria Indígena № 26.160. Además de declarar la emergencia en materia de posesión y propiedad de las tierras que tradicionalmente ocupan las comunidades indígenas del país, la ley prevé la realización de un relevamiento técnico jurídico y catastral de las ocupaciones "tradicionales, públicas y actuales". Desde los inicios de la implementación del Programa, se evidenció la polisemia de significados y sentidos que la idea de "territorio" presupone para los actores que intervienen en el proceso de relevamiento, tanto funcionarios como técnicos y comunidades indígenas. Este artículo analiza de qué forma la implementación de la Ley № 26.160 puso en relación nociones de territorio y prácticas de territorialidad a partir de la actualización de memorias sobre el espacio realizadas por miembros de comunidades mapuche en conjunción con nociones provenientes de otras agencias no indígenas.
\end{abstract}

Palabras clave: Mapuche, Norpatagonia, Argentina, relevamiento territorial

\begin{abstract}
In November 2006, the National Congress of Argentina enacted the Emergency Law of Indigenous Community Property, No. 26.160. The Law declared an emergency concerning the different forms of possession and ownership of lands traditionally occupied by indigenous communities in the country. At the same time, the Law proposes the implementation of a legal and technical land registry survey of the "traditional, public and current occupations". From the moment of implementation of the Law, there has been evidence as to the multitude of definintions and meanings that the idea of "territory" has for the actors -official agents, technicians and indigenous communities- involved in the survey process. In this paper we analyze how the implementation of Law No. 26.160 has provoked a modernization in the notion of territory and territoriality based on an update in spatial memories held by members of the mapuche community that are at the same time entangled with those perceptions produced by non-indigenous agencies.
\end{abstract}

Key words: Mapuche, Northern Patagonia, Argentina, territorial survey

\footnotetext{
Esta investigación cuenta con el apoyo del Consejo Nacional de Investigaciones Científicas y Técnicas (CONICET). Artículo recibido el 12 de mayo de 2015, aceptado el 17 de agosto de 2015 y corregido el 11 de septiembre de 2015.
}

\footnotetext{
2 Instituto de Investigaciones en Diversidad Cultural y Procesos de Cambio (IIDyPCa), CONICET-Universidad Nacional de Río Negro (Argentina). E-mail: kaniukeupu@gmail.com
} 
El Programa Nacional de Relevamiento Territorial de Comunidades Indígenas fue diseñado a partir de la sanción de la Ley 26.160 en el año 2006 en Argentina. Tiene como objetivo realizar la demarcación de los territorios de las comunidades "para generar las condiciones tendientes a la instrumentación del reconocimiento de la posesión y propiedad comunitaria" (INAI, s/f: 5). El Programa comprende más de treinta pueblos indígenas en todo el país. Para implementarlo dentro de sus jurisdicciones, cada uno de los estados provinciales debe adherir a la Ley Nacional. En ese marco, la provincia patagónica de Río Negro se sumó a la implementación de la Ley 26.160 en el año 2007 y designó al Consejo de Desarrollo de Comunidades Indígenas (Co.De.C.I.) como organismo ejecutor ${ }^{3}$.

En la provincia de Río Negro, la presencia más numerosa es la del Pueblo Mapuche que abarca a un gran número de comunidades, organizaciones y familias en todo el territorio provincial. Para implementar el Programa de Relevamiento se elaboró un listado de más de cien comunidades, al que se sumaron los pobladores indígenas denominados "dispersos". Transcurridos los dos primeros años del Programa, se evidenciaron como problemáticas ciertas nociones que repercutieron directamente en la implementación de los relevamientos, tales como territorio, ocupación tradicional, actual y pública, lof, lofche y comunidad ${ }^{4}$. La necesidad de abordar estas nociones surgió tanto de parte del equipo téc-

3 Organismo de cogestión estatal e indígena que aplica la Ley provincial Integral del Indígena $N^{\circ} 2287$. Surge como resultado del proceso de movilización mapuche de fines de la década de 1980 y tiene competencia en la aplicación de políticas públicas destinadas a la población indígena que vive en la provincia de Río Negro.

4 Lof y lofche son nociones que refieren a la organización social mapuche y suelen ser traducidas al castellano como "comunidad", aunque su sentido entre los mapuche es polisémico. Ambas vinculan articulación y agenciamiento de grupos mapuche (familias, linajes, comunidades ceremoniales, etc.) con procesos de territorialización. Al este del Territorio Mapuche (en Puelmapu), esta definición fue debatida durante la década de 1990 por la Coordinación Tayiñ Kiñegetuam (1995), transformándose en una categoría analítica. El objetivo que guió ese debate fue cuestionar la idea de "tribu" dando nico designado para la tarea de relevamiento, como desde las comunidades. Estas últimas formularon quejas a sus representantes por la forma de producción de los datos y apuntaban, principalmente, a la elaboración de las cartografías. Entre otras cosas, se criticaba que los mapas no incluyeran el despojo histórico, redujeran considerablemente lo que era reivindicado como territorio "tradicional" o no reflejaran la conflictividad en la ocupación.

Tomando en cuenta estas demandas, algunos representantes mapuche propusieron evaluar la implementación del Programa mediante talleres que se realizaron entre los años 2011 y 2012. De estos talleres participaron técnicos, representantes gubernamentales, miembros de comunidades, activistas y profesionales indígenas y no indígenas. La evaluación se enfocó en todas las etapas del Programa e incluyó un interés especial por la revisión de los conceptos utilizados para acordar sus usos operativos. Entre otras cosas, ese debate implicó revisar las propias nociones metaculturales sobre identidad, pertenencia y territorio que fueron discutidas por las organizaciones mapuches en Argentina durante la década de 1990.

Este trabajo retoma algunos de los debates surgidos en esos talleres. La pregunta que lo guía es ¿qué nociones de territorio, ocupación y uso se (re)definen entre miembros de comunidades mapuche en el marco de la aplicación de políticas estatales de relevamiento territorial? Para contextualizar estos debates se comenzará por dar cuenta de las formas de ocupación espacial habilitados para los indígenas entre fines de siglo XIX y durante el siglo $X X$ que se tornan relevantes en el presente. Particularmente, se analizará cómo el "desierto", en tanto dispositivo, sirvió para crear un imaginario sobre una extensión de tierras sin colonizar y para reforzar los principios de la matriz Estado-naciónterritorio que tuvo como imperativo la conquista de los territorios indígenas (Navarro Floria, 2007; Briones \& Delrío, 2009; Delrío y Pérez, 2011). 
Asimismo, se describirán los fundamentos del Programa de relevamiento territorial para luego abordar algunas de las categorías que se problematizaron en los talleres. De esta forma, se espera poder dar cuenta del proceso de disputa de concepciones de territorialidad que se ponen en juego a partir del relevamiento territorial de comunidades indígenas en una provincia caracterizada por una particular dinámica regional: la zonificación. En tanto proceso de dominio político-económico y de apropiación simbólico-cultural del espacio (Sack, 1986; Haesbaert, 2007), la zonificación es la forma privilegiada en que opera la territorialización en Río Negro. Como veremos, las zonas señalan una práctica de control que organiza conceptual, programática e ideológicamente a la provincia. Al mismo tiempo, el resultado de esas operaciones territorializadoras y estratificadoras (Grossberg, 1992) condicionan la manera en que se distribuyen los actores y restringe las movilidades, indicándoles por dónde circular.

\section{La "Campaña del Desierto": estructuración de fronteras y regiones en Norpatagonia}

Las avanzadas militares de ocupación de los territorios indígenas realizadas entre 1878 y 1885 son unificadas bajo la denominación de "Campaña del Desierto". Tanto estas operaciones militares como las posteriores, representan un quiebre en las pautas de autonomía y en las formas tradicionales de organización sociopolítica para los pueblos indígenas. Al mismo tiempo, inaugura en el seno de la estructura de la matriz Estado-nación-territorio argentino una forma de territorializar que tienen efectos en el presente y definen límites en dos sentidos: tanto "hacia afuera", respecto a otras naciones, como "hacia adentro" de la nación, configurando fronteras internas y produciendo regiones en el marco de un programa geopolítico (Benedetti, 2009).

Ya desde los inicios de la planificación del avance militar sobre una difusa región denominada Patagonia, la preocupación por demarcar los límites, las fronteras y la ubicación de la población indígena ha sido parte de las agendas gubernamentales. Con mayor o menor énfasis, esa preocupación se ha mantenido a lo largo del siglo XX. Silvina Quintero, al analizar los procedimientos de construcción de las regiones en Argentina, apunta que el fundamento de una regionalización es la "conceptualización del objeto" que, en el marco de la generación de configuraciones territoriales estatales, terminan creando divisiones que operan como "dispositivos de diferenciación geográfica" (Quintero, 2002: 4). Puntualmente, el reforzamiento de la Patagonia como región estableció como hito de avance de la civilización -respecto del centro bonaerense- las márgenes de los ríos Negro y Neuquén. Esa delimitación estuvo implementada en varios niveles que comprendieron dispositivos de control y demarcación que avanzaron sobre un territorio presumido como nacional. Asimismo, sirvieron para la creación de un imaginario que subdivide y diferencia un territorio en base a "atributos naturales".

Desde mediados del siglo XVI se venían estableciendo una serie de pactos, acuerdos y convenios entre representantes de la Corona española, primero, y en tiempos republicanos, después, con distintos grupos y representantes indígenas (Briones y Carrasco, 2000). Se reforzaba así una idea de frontera que partía de una clara demarcación con el "otro" indígena con un estatus legal que reconocía, a su vez, jurisdicciones territoriales diferenciadas entre sí. Aun cuando esa relación se basara en el intercambio, en alianzas y negociaciones, la demarcación de los límites fronterizos no estuvo exenta de conflictos. Esos mismos conflictos servirían como fundamento para que, en el marco de la consolidación del Estado moderno argentino, las elites construyeran la idea de que esas otras poblaciones como sus territorios fueran pasibles de ser sometidos a una jurisdicción nacional (Bechis, 1992). Hacia mediados de siglo XIX la política hegemónica estatal, guiada por los principios de la denominada "Generación del 80 ", viró hacia erradicar toda red de circulación indígena por el espacio para asegurar la expansión estatal. Esta necesidad concentró los esfuerzos de intelectuales, estadistas, funcionarios y agentes privados que fueron organizando y diferenciando actores y fijando una simbolización particular sobre ese espacio a colonizar.

La imagen más potente utilizada para marcar diferencias internas y fronteras en los 
tiempos previos a las campañas militares fue la del "desierto" -erigido como periférico en relación a un autoproclamado centro civilizado establecido en Buenos Aires-, esto es, como un vacío que era necesario explorar, conocer y colonizar (Zusman y Minvielle, 1995). Esa imagen fue clave para definir los tropos de "civilización y progreso" en oposición a la "barbarie". Fue bajo esta lógica que se organizó la incorporación y el sometimiento indígena al orden nacional por medio de la violencia y la ocupación militar del territorio a fines del siglo XIX.

La persecución de las comunidades indígenas, los destierros, el confinamiento en campos de concentración a lo largo del río Negro (Delrío, 2005; Pérez, 2014) o en la isla Martín García (Nagy y Papazian, 2009), los posteriores desmembramientos familiares, los traslados masivos a pie y la disposición arbitraria de personas como mano de obra esclava de familias aristocráticas bonaerenses e incipientes centros económicos (Mases, 2002), así como la reclusión de familias en museos e iglesias respondieron a una misma lógica de disciplinamiento social. La antropóloga Diana Lenton resalta que estas prácticas no solo fueron dirigidas a los indígenas, sino que también implicó una manifestación del biopoder en la sociedad en general (Lenton, 2005). Las características de su aplicación encuadra en la figura del delito de genocidio que, al presente, sigue siendo negado como evento fundante de la matriz estatal argentina (RIG, 2010). En tanto dispositivo, el "desierto" tuvo un impacto profundo en la organización del espacio, así como en la implementación de prácticas de ciudadanía diferenciadas. De variadas formas, ese dispositivo y sus efectos continúan ejerciendo un poder ordenador en el presente.

\section{La radicación de los pueblos indígenas en Norpatagonia}

Una vez que las tierras indígenas fueran incorporadas a la jurisdicción del territorio nacional se inicia un proceso de disputa en pos de definir las pautas de control del espacio. De acuerdo con el historiador Walter Delrío, tanto la distribución, como el acceso al principal recurso provisto por las campañas militares -la tierra-, fueron definiéndose en una arena donde autoridades estatales, elites locales, agencias privadas y grupos indígenas disputaron lineamientos y estrategias. Por esa razón, los mecanismos de radicación de los indígenas no deben rastrearse solamente en las leyes destinadas a ellos, sino también en aquellas que regularon la colonización de las tierras incorporadas (Delrío, 2005: 121). Entre esas leyes se cuentan las de inmigración y colonización, de venta de tierras fiscales, de concesión para la ganadería y de premios militares que subdividirán y ordenarán un espacio conquistado aunque inacabadamente conocido (Briones y Delrío 2002: 53). Asimismo, establecerá jerarquías en el tipo de colonización "deseable", distinguiendo entre argentinos sin tierra, extranjeros prontos a ciudadanizarse, compradores potenciales $y$, finalmente, indígenas. El ideal a concretar será la generación de un modelo de producción capitalista de matriz agrícola y ganadera propiciada por colonos. Sin embargo, ese cuerpo legal pensado desde el centro del poder bonaerense no será siempre coherente y generará contradicciones al interior de los territorios nacionales creados en la Patagonia ${ }^{5}$, reflejada en las miles de hectáreas que serán abandonadas y en la formación de latifundios.

Entre las formas de radicación que afectaron a la población indígena, podemos mencionar las leyes especiales dirigidas a establecer grupos indígenas reagrupados en torno a "caciques". El reagrupamiento de familias con diferentes trayectorias en torno a figuras reconocibles para el Estado -el "cacique"- fue una estrategia que resultó exitosa para la agencia indígena en un contexto de violencia. Pese a la gran vulnerabilidad que implicaba el apresamiento en los campos de concentración, fue allí donde algunos líderes reconocidos por el Estado pudieron negociar algunas entregas de tierra. No obstante, la conformación de los grupos y el destino en el que fueron reubicados estaba determinado por las autoridades argentinas. Es por ello

\footnotetext{
5 En 1884 se sanciona la Ley Nacional 1.532 que organiza y divide la anterior "Gobernación de Patagonia" en seis Territorios Nacionales dependientes del Poder Ejecutivo Nacional. Así, se crean los Territorios Nacionales de La Pampa, Neuquén, Río Negro, Chubut, Santa Cruz y Tierra del Fuego que se convertirán en Estados Provinciales recién en la década de 1950.
} 
que aquellos que recibieron tierras -lo que constituyó casi un privilegio- fueron localizados en zonas que representaban escaso interés productivo (Salomon Tarquini, 2010).

Como parte de la política de anexión de los territorios indígenas, podemos citar la Ley 1.532 -sancionada en 1884-que subdividió a la Patagonia en Territorios Nacionales dependientes del Estado nacional. Entre otras cosas, establecía que cada Gobernador de Territorio debía procurar establecer "las tribus indígenas que morasen en el territorio de la gobernación", para lo que se crearían "misiones", previa autorización del Poder Ejecutivo Nacional (Art. 11). Así, se establecía que la política a seguir con los indígenas era "fijar" como forma de "civilizar" 6 .

Dentro del Territorio Nacional de Río Negro, y en el marco de esta ley, algunos indígenas consiguieron concesiones individuales, mientras que otros gestionaron tierras para la radicación de grupos indígenas. Este tipo de entregas hechas a un "cacique" y su "tribu" convivió con otras formas de radicación en colonias agrícolas pensadas originalmente para radicar argentinos sin tierra y extranjeros prontos a ciudadanizarse. Esas colonias venían siendo promovidas por la Ley 1.501 de 1884, que establecía la creación de lotes de 625 hectáreas. Desde el Estado Nacional se preveía que estas colonias fueran ampliadas, para lo cual se pusieron en resguardo fracciones de tierras en "reserva". Sin embargo, esa política quedaría sin efecto y comenzaría un proceso de solicitud individual que fraccionaría a las colonias (Delrío et al., 2014). Esas tempranas ambigüedades en la legislación, sumadas a las que sobrevinieron en la etapa de provincialización ${ }^{7}$, generaron conflictos

\footnotetext{
6 El régimen de "misiones" se sostendrá en el tiempo como solución para grupos indígenas vistos como altamente "alterizados", es decir, ubicados en el extremo opuesto de la "civilización". Pese a que estaban contempladas en la Ley 1.532, las misiones no fueron aplicadas a los grupos mapuche. Estos serían radicados a través de leyes especiales o a partir de ser incluidos en otras legislaciones que regían para el resto de la población no indígena.

7 Conforme se fue gestando la tarea de una estructura federal organizada en estados provinciales, los territorios nacionales fueron "provincializados", lo que significaba la independencia administrativa del Po-
}

en el modo de ocupación espacial de los indígenas ${ }^{8}$.

Mediante la Ley 1.501 también se adjudicó tierras a inversores que debían cumplimentar ciertos requisitos, tales como la radicación, el cultivo y la introducción de mejoras. Sin embargo, fueron cuantiosos los que faltaron a ese compromiso y, aun así, lograron excepciones por normas posteriores. Este tipo de entregas originarían concentraciones de tierras, como las puestas en mano de la Compañía Argentina de Tierras del Sud, de capitales ingleses ${ }^{9}$. Serían numerosos los indígenas que se incorporarán a las estancias de esta Compañía como peones rurales.

Paralelamente, otros grupos indígenas fueron atomizados por el Estado y no hubo para ellos asignación de tierras ni reconocimientos en términos colectivos. Como resultado, sus miembros debieron tramitar individualmente la tenencia buscando ser reconocidos como ocupantes individuales de las devenidas "tierras fiscales"-invisibilizando sus formas colectivas de organización-. Muchos de ellos no pudieron cumplimentar con los requisitos impuestos por el Estado y se vieron, nuevamente, expulsados de sus tierras. Fueron estos colectivos de menor visibilidad social quienes se encontraban en una situación de alta vulnerabilidad, pues el reconocimiento a su ocupación estaba condicionado a criterios racistas. Pese a la evidente fragmentación social, los colectivos indígenas continuaron siendo útiles como imagen de la antítesis del progreso y construidos eventualmente como un peligro inminente para la seguridad de la nación y el desarrollo capitalista, fundamen-

der Ejecutivo Nacional y del Senado de la Nación. La provincialización de Río Negro data de 1955.

8 Para el caso mapuche, la división entre dos Estados nacionales -Chile y Argentina- y, por lo menos, cinco provincias -Buenos Aires, La Pampa, Neuquén, Río Negro y Chubut- ha complejizado aún más los tipos de ocupación dado que cada estado provincial ha configurado formas propias de delimitar los espacios y sus usos.

9 Esta Compañía determinará la organización espacial de la región. Por ejemplo, varios puntos del trazado ferroviario se diseñaron en torno a estancias ganaderas propiedad de la Compañía para asegurar el traslado de productos hacia los puertos del Atlántico, en detrimento de las salidas hacia el Pacífico (Delrío et al., 2014). 
tado en una supuesta inhabilidad productiva (Radovich y Balazote, 1995). Esa construcción que predominó entre funcionarios estatales y se extendió como sentido común en el resto de la población, sirvió como refuerzo de un ideal de nación y de una matriz de distribución espacial que confinó a las poblaciones sobrevivientes a las tierras de mayor marginalidad productiva. De hecho, estos mismos argumentos serían retomados durante el siglo XX para justificar desalojos y persecuciones.

\section{Las "zonas" y los "dispersos" en las formas de territorialización en Río Negro}

La provincia de Río Negro está definida por una regionalización intraprovincial definida por una lógica de subdivisión en zonas. Es a partir de esa lógica que, de oeste a este, la provincia se divide y planifica en cuatro zonas: Andina al oeste, Sur o Línea Sur -denominada así por el trazado del ferrocarril del sur que atraviesa transversalmente la provincia-, Valle -subdividida en Alto Valle, Valle Medio y Valle Inferior- y Atlántica en el extremo este del territorio provincial (ver Figura $N^{\circ} 1$ ). En base a estas zonas se organiza y se programan gran parte de las políticas estatales. Pero también, forman parte de un sentido compartido entre los habitantes rionegrinos de diferenciar la provincia. Ese sentido fue moldeado desde los inicios de la provincialización rionegrina y sigue siendo reproducido por diferentes organismos. Por ejemplo, un informe difundido por el Área de Información General de la Casa de Río Negro en Buenos Aires dice que:

"Con la conquista del desierto, la población indígena se recluye en reserva en la zona centro-sur, fundamentalmente. Así la zona del Valle recibe una afluencia de españoles e italianos a partir de 1915. Obviamente, el fenómeno migratorio en esta zona incluye ingleses, yugoslavos, checoslovacos, rusos, etc. Este fenómeno también se repite en el Valle Inferior (zona de Viedma). En la zona Centro-Sur aparece la mayor concentración de habitantes con ascendencia árabe de la provincia. En cambio, en la Zona Andina este fenómeno se da con población de origen alemán, suizo, austríacos, etc., que buscaron en la zona de los lagos y los bosques un paisaje y clima similar al de su país natal. Obviamente, en todos los casos, la presencia española e italiana también es importante. En resumen, Río Negro puede decir que, a pesar de su reducida población, posee una variada gama de razas y nacionalidades que conviven en armonía" (A.I.G.C.R.N., 1994:11, subrayado propio).

Por lo menos hasta la década de 1970, esa zonificación se basaba en la idea de que las divisiones eran producto de elementos naturales, como el clima y la vegetación, que condicionan y determinan causalmente las relaciones sociales, económicas y políticas e imprimen subjetividades específicas a cada zona (AAVV, 1974). La confluencia de perspectivas naturalistas, deterministas $y$ fenomenológicas presenta a las zonas como albergando "naturalmente" y en "armonía" a poblaciones diversas que en apariencia no tienen ningún contacto -ni conflicto- entre sí. En la misma lógica, la acción de "recluirse" aparece como una decisión adoptada por las poblaciones indígenas, desconociendo así el complejo proceso de territorialización provocado por la incorporación violenta de sus territorios.

Esta misma lógica establece que es a la Línea Sur donde se apuntan los mayores esfuerzos de intervención estatal, cuya población se encontraría en un nivel "inferior" de desarrollo respecto de las otras zonas. Justamente, es en esa zona donde las políticas oficiales han fijado a los indígenas (Cuadro $N^{\circ} 1$ ). Dentro de esta zona la ganadería intensiva, que constituye el motor económico de la región, es naturalizada como una práctica tradicional indígena pese a que su implementación está ligada al modelo exportador propulsado por grandes compañías ganaderas. De esta manera, al deshistorizar procesos, estos discursos fijan movilidades en un doble sentido: esencializando atributos culturales, económicos y políticos y determinando un espacio unívoco para los indígenas. La articulación entre subdesarrollo económico y alterización acaban naturalizando un supuesto "atraso" de la población indígena. Así, la zonificación opera performativamente, guiando la acción de actores e instituciones y espacializando subjetividades. 
Figura $N^{\circ} 1$

Territorio de la provincia de Río Negro y subdivisión regional por zonas e identificación de comunidades indígenas relevadas por el Programa de Relevamiento Territorial
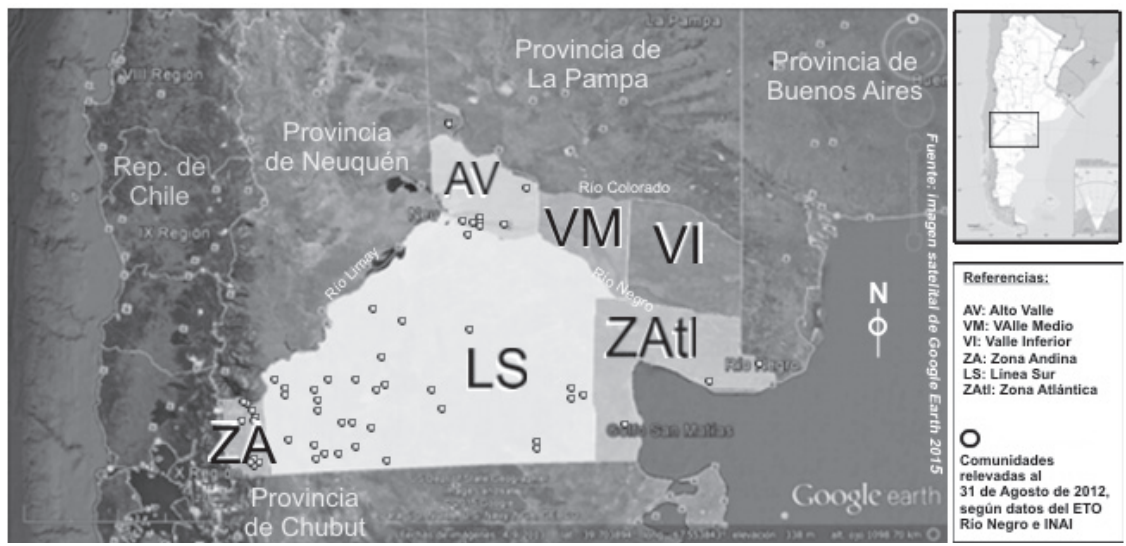

Fuente: Elaboración propia en base a datos extraídos de la página oficial del Gobierno de Río Negro y datos proporcionados por el INAI.

Cuadro $N^{\circ} 1$

Listado de reservas indígenas en la provincia de Río Negro

\begin{tabular}{|l|r|}
\hline Reservas sin reconocimiento de leyes provinciales & \multicolumn{1}{|c|}{ Total de hectáreas entregadas } \\
\hline Anecón Grande & 17.000 \\
Nahuelpan & 1.162 \\
Atraico & 11.135 \\
Total de hectáreas & 29.297 \\
\hline Reservas con reconocimiento de leyes provinciales con & Total de hectáreas entregadas \\
Escrituras de Usufructo Gratuito y Vitalicio / Año & 8.350 \\
\hline Yuquiche / 1973 & 23.454 \\
Cañumil /1987 & 31.804 \\
Total de hectáreas & 28.383 \\
\hline Reservas con reconocimiento de leyes provinciales Sin & Total de hectáreas entregadas \\
Escrituras de Usufructo Gratuito y Vitalicio / Año & 157.150 \\
\hline Ancalao / 1971 & 29.400 \\
Lipetrén /1971 & 20.000 \\
Nazario Chico / 1971 & 110.600 \\
Chaiful / 1972 & 3.500 \\
Pilquiniyeu del Limay / 1972 y 1987 & 349.033 \\
Cerro Bandera / 1973 & 410.134 \\
Total de hectáreas & \\
Total de hectáreas en reserva indígena en Río Negro & \\
\hline
\end{tabular}

Fuente: Elaboración propia en base a datos contenidos en UNC-APDH (1996) y Dirección General de Tierras de Río Negro (2000). 
Las once "reservas indígenas" que existen en Río Negro se ubican en la Línea Sur. Si tenemos en cuenta que la superficie total de la provincia es de $203.013 \mathrm{~km}^{2}$, las tierras en "reserva" suman un $2,02 \%$ del total ${ }^{10}$. Solo en dos de ellas se entregaron las escrituras de "Usufructo Gratuito y Vitalicio" que las leyes de creación de reserva establecieron. Seis de ellas no cuentan con la entrega de esas escrituras y otras tres reservas no fueron reconocidas por leyes provinciales. A eso se suma la reducción territorial por la entrega de títulos a terceros no indígenas sobre esas reservas o la afectación para proyectos económicos ${ }^{11}$.

El ordenamiento espacial rionegrino es apropiado por distintos sectores en la provincia que replican isomórficamente la distribución de los tipos de intervención por zonas (Cañuqueo et al., 2005). De hecho, las organizaciones indígenas se identifican y se estructuran en comunidades agrupadas por zonas con características diferenciadas entre sí. Desde la perspectiva compartida por la gran mayoría de los indígenas que participan del ámbito de la Coordinadora del Parlamento del Pueblo Mapuche ${ }^{12}$, es en la Línea Sur donde vive la población indígena organizada en "comunidades". Sugerentemente, ese carácter estaría dado por el reconocimiento estatal que fijó poblaciones en torno a la idea de "caciques" junto a sus "tribus" para otorgar reconocimientos.

La noción de "comunidad" en Río Negro es un proceso de articulación intertextual emergente de la demanda de derechos del movimiento mapuche durante la década de

${ }^{10}$ Cabe destacar que la información generada por el estado rionegrino sobre la población indígena no está unificada y está desactualizada.

${ }^{11}$ Por ejemplo, 10.000 ha de la reserva Indígena de Pilquiniyeu del Limay fueron afectadas en el año 1990 por la construcción de la represa hidroeléctrica Piedra del Águila, propiedad de la empresa Hidroeléctrica Norpatagónica S.A. (HIDRONOR). Por una ley posterior, y fruto de la movilización indígena y de diferentes sectores, se logró expropiar una superficie de 60.000 ha a la Estancia María Sofía S.A.

${ }^{12}$ La Coordinadora del Parlamento del Pueblo Mapuche fue creada en 1997 y reúne a comunidades, organizaciones y Centros Mapuche de distintas localidades y parajes de la provincia de Río Negro.
1990 en Argentina, que tuvo a la "cultura" como tópico de los planteamientos políticos. Como resultado de esa disputa, el discurso mapuche que ha tenido más difusión en los últimos años es aquel promovido por la Coordinación de Organizaciones Mapuche Tayiñ Kiñegetuam -Para volver a ser uno- que define al Lof como la forma de organización comunitaria mapuche "tradicional". Según esa definición, el Lof es "punto de origen e identidad de cada persona" (TKG, 1995: 4) donde conviven las familias. Cada Lof ocupa una "unidad territorial" (TKG, 1995: 4) espacializado en el Wallmapu, "ancestral territorio" y origen de la "identidad colectiva mapuce [sic.]" (TKG, 1995: 4).

Además de los antecedentes mencionados, se suman categorías contenidas en la Ley Nacional $N^{\circ} 23.302$, la Ley Provincial $N^{\circ}$ 2.287, el Convenio 169 de la Organización Internacional del Trabajo y el Artículo 42 de la Constitución Provincial rionegrina. El Co.De.C.I. define a la comunidad mapuche como los "conjuntos de familias que se reconozcan" como tal y que deben "descender de pueblos originarios" que "habitaban el territorio de la Provincia de Río Negro en la época de la conquista o colonización" (Co. De.C.I., 2006: 1). De esta manera, las comunidades indígenas comparten "pautas culturales"-como el idioma-, viven en un "hábitat común" y tienen "autoridades designadas" (Co.De.C.I., 2006: 2-3). En Río Negro esa organización "propia" tiene su contrapuesto en los mapuches "dispersos".

La categoría de "disperso" fue incluida por primera vez en la Ley Integral del Indígena $N^{\circ} 2287$ en 1988. Se refiere a la forma de nucleamiento de las comunidades y al tipo de asentamiento en la que viven sus miembros caracterizados como "asentamientos nucleados o dispersos" (Art. 3). Su génesis está enmarcada en un proceso de disputa entre el Consejo Asesor Indígena y el gobierno provincial en la década de 1980. La inclusión de las comunidades "dispersas" apuntaba a visibilizar a la población que no había logrado ser reconocida por decretos de reserva para ser "concentrada", es decir, a la gran mayoría (Cañuqueo, 2015).

Si bien nace como fruto de la demanda indígena, en la actualidad la noción de "dis- 
persión" interpela a la pertenencia de un individuo y no a la característica del asentamiento de una comunidad, como lo planteaba la Ley $\mathrm{N}^{\circ}$ 2.287. Concretamente, se refiere a pobladores mapuche que no integran ninguna comunidad reconocida legalmente por el Estado. Para las organizaciones mapuche la ausencia de reconocimiento equivaldría a la falta de organización comunitaria y, casi por decantación, generaría una "pérdida" de la "riqueza cultural" (Co. De.C.I., 2006: 2). El hecho de no haber obtenido un reconocimiento estatal en términos de colectivo indígena, aunque lo hayan gestionado en diferentes formas y épocas, coloca a muchas comunidades en una posición desigual frente al Estado y ante otras comunidades reconocidas legalmente. Para las organizaciones mapuche, la zonificación y un tipo de "comunidad" distingue subjetividades y formas de participación política que instituye, por ejemplo, representantes indígenas por zona.

\section{Ley Nacional 26.160: su implementación en la provincia de Río Negro}

Según su decreto reglamentario, la Ley Nacional de Emergencia de la Propiedad Comunitaria Indígena $N^{\circ} 26.160$ vino a saldar los compromisos asumidos tanto a nivel internacional como nacional. Basándose en esos compromisos, los objetivos principales son:

1. "declarar la emergencia en materia de posesión y propiedad de las tierras que tradicionalmente ocupan las comunidades indígenas originarias del país" (Art. $1^{\circ}$ )

2. "realizar el relevamiento técnico-jurídicocatastral de la situación dominial de las tierras ocupadas por las comunidades indígenas" (Art. $3^{\circ}$ ).

En función de ejecutar el relevamiento, el Instituto Nacional de Asuntos Indígenas -organismo responsable de la ejecución de la Ley- diseñó un Programa Nacional de Relevamiento Territorial de Comunidades Indígenas, cuyos lineamientos se difunden a través de un manual.

\section{El Programa Nacional de Relevamiento Territorial de Comunidades Indígenas}

El Programa de Relevamiento Territorial funda la necesidad de relevar y demarcar los territorios de las comunidades indígenas como paso previo a la "instrumentación del reconocimiento de la posesión y propiedad comunitaria" (INAI, s/f: 5). La Ley 26.160 establece que las comunidades indígenas a relevar deben sostener una ocupación "actual, tradicional y pública" (en adelante, OATP) que debe ser fehacientemente acreditada (Art. $2^{\circ}$ ).

Por "actual" se entiende la ocupación "definida al momento de la sanción de la Ley $N^{\circ} 26.160$ [año 2006], quedando excluido de esta clasificación todo espacio que corresponda a recuperaciones o incorporaciones realizadas con posterioridad a dicha sanción" (INAI, 2011: 7) 13. Los territorios ocupados con posterioridad a 2006 son relevados como de "Ocupación Tradicional y Pública", pero no "actual" (OTP). Pueden ser relevados como OATP los territorios que hubieran sido despojados durante la vigencia de la ley, siempre que el hecho haya sido documentado. Si el despojo no puede ser demostrado, entonces se releva la ocupación como "Territorio Comunitario en Conflicto". Si el despojo data de antes de 2006, se elabora una "Cartografía de la Memoria".

En el manual del Programa el "territorio tradicional" es definido como "espacios habitados por pueblos indígenas" y delimitados por "hitos geográficos reconocidos socialmente por una o más agrupaciones de una misma etnia o de otra distinta". Esos territorios tradicionales tienen una "jurisdicción" que es "gobernada por un representante de la comunidad, regida por normas y leyes propias". En tanto, el espacio se organiza "en base a las relaciones de parentesco", donde los linajes determinan los usos mediante la "tradición y la herencia" (INAI, s/f: 26).

\footnotetext{
13 La imposición de un límite temporal es criticada por sectores vinculados a la defensa de Derechos Indígenas, pues se entiende que contradice el reconocimiento realizado a "las tierras que tradicionalmente ocupan" las comunidades contenido en el Artículo 75, inciso 17, de la Constitución Nacional.
} 
Finalmente, la condición "pública" de la ocupación remite a que debe ser conocida por terceros distintos a los miembros de la comunidad relevada.

El relevamiento de la OATP de las comunidades indígenas de la Argentina implica la toma de datos por parte de un Equipo Técnico Operativo (en adelante, ETO) que se constituye en cada provincia y está integrada por:

a) representantes indígenas en el Consejo de Participación Indígena (CPI) y los designados dentro de cada provincia;

b) agrimensores y/o geógrafos que conforman el Área de Georreferenciamiento;

c) antropólogos y trabajadores sociales que integran el Área Social;

d) abogados encargados del Área Legal y, finalmente,

e) administrativos y contadores encargados de la administración de los fondos.

El ETO es una instancia técnico-política encargada de relevar información acerca de los antecedentes de ocupación y del uso que las comunidades indígenas dan a su territorio, así como datos sobre su estructura social. El objetivo del ETO es Ilegar a elaborar lo que se denomina "carpeta técnica" que contiene el relevamiento técnico, jurídico y catastral del territorio de cada comunidad. Es en base a esa carpeta que el INAI elabora el dictamen final que define el estatus de la ocupación de los territorios indígenas. El punto de partida es que "cada pueblo tiene un control y apropiación particular del espacio", siendo "los procesos sociales imperantes en cada pueblo" los que definen la "organización espacial y las formas de apropiación del territorio" (INAI, s/f: 19). Su trabajo se divide en dos momentos: uno que se denomina "en terreno", en el que la información es recopilada junto a las comunidades, y otro que es Ilamado "en gabinete", que consiste en la elaboración de los informes y de las cartografías.

En terreno, el Área de Georreferenciamiento redacta un texto que denomina "Narrativa" en el que se enumeran, sin detallar, los usos económicos, sociales y culturales del territorio a partir de los datos proporcionados por los miembros de la comunidad. Se apunta a que esos usos permitan identificar circui- tos y objetos con "atributos" que puedan ser espacialmente localizados para elaborar un croquis. Esos datos orientan el levantamiento de puntos con el Sistema de Posicionamiento Global (GPS, por sus siglas en inglés) que luego serán incorporados a las cartografías. A su vez, estas serán incorporadas al Sistema de Información Geográfica de las Comunidades Indígenas que almacenará la información de las ocupaciones ejercidas por los indígenas de todo el país. También es en esta etapa de trabajo donde el Área Social recopila información para la elaboración del Informe Histórico Antropológico (ver más abajo) y realiza el cuestionario sociocomunitario de comunidades indígenas (CueSCl).

El trabajo en gabinete consiste en la confección de la "cartografía del Territorio Comunitario, con todos los usos del suelo relevados" (INAI, s/f: 49). Todos los tipos de cartografías especificados anteriormente (OATP, OTP, "Territorio en Conflicto" y "Cartografía de la Memoria") deben ser elaboradas como resultado de las entrevistas realizadas en terreno y del informe jurídico que realizan abogados a partir del estudio de títulos y otros documentos de reparticiones estatales. Eventualmente, se pueden adjuntar otras cartografías que evidencien datos de ocupación superpuestas con otras entidades públicas. Por ejemplo, aquellas comunidades que ocupan áreas protegidas bajo el ejido de estados municipales o provinciales o en jurisdicción de Parques Nacionales. Cada carpeta técnica es acompañada por un Informe Histórico Antropológico que "no es una pericia" ni una "investigación en términos académicos", aunque emplea "métodos y técnicas de investigación" (INAI, s/f: 53) y que sirve para una eventual instancia judicial posterior. Este informe debe dar cuenta de la relación material y simbólica que las comunidades mantienen con los territorios de OATP, concentrándose en el "uso y posesión del territorio" (INAI, s/f: 51 y 52) y en sus condiciones históricas de ocupación.

La implementación en la provincia de Río Negro

En 2007, la provincia de Río Negro adhirió a la Ley Nacional 26.160 y hasta 2012 el ETO provincial fue coordinado por representantes y contó con asistentes técnicos mapu- 
che. Siguiendo la lógica de la zonificación, la Coordinadora del Pueblo Mapuche de Río Negro designó a sus técnicos diferenciándolos por zonas (valle, atlántica, sur y andina). Esas mismas divisiones fueron utilizadas para distribuir las 126 comunidades y pobladores dispersos a relevar.

En virtud de la constitución del ETO, la provincia de Río Negro es una de las que posee una mayor y más activa participación de miembros indígenas, lo que permite una "negociación de estos agentes con el Estado nacional y provincial para reformular y redefinir cuestiones básicas planteadas en el manual de relevamiento" (Guiñazú, 2012: 6) ${ }^{14}$. Esa negociación se comenzó a evidenciar en marzo de 2012, cuando la coordinación del ETO convocó al taller que trataría exclusivamente la revisión de los conceptos utilizados en la Ley 26.160. La dinámica estuvo definida por la preocupación sobre la definición de las nociones de lof, lofche, comunidad, territorio, ocupación tradicional, actual, pública y poblador disperso. Bajo la denominación de "Taller-encuentro de pensamiento y cosmovisión mapuche" se convocaron a comunidades y organizaciones de la provincia.

El taller fue organizado en dos grupos: uno con hablantes del mapuzungun [idioma mapuche] y otro conformado por miembros del ETO provincial, comunidades e integrantes de la Coordinadora. El supuesto que motivó a convocar a un grupo de personas hablantes del idioma mapuche fue que a través del idioma se podrían definir concepciones tradicionales mapuche sobre modos de ocupar el espacio y la organización comunitaria (como lof o lofche). Sin embargo, más que concentrarse en definiciones, la reflexión derivó en las trayectorias colectivas en relación al espacio, vinculándolo con los desplazamientos propios y los transmitidos por las anteriores generaciones.

\footnotetext{
14 Actualmente, en Río Negro, el Programa de Relevamiento se encuentra suspendido, dado que el convenio firmado concluyó en 2012. La firma de un nuevo convenio está pendiente de aprobación.
}

\section{El debate de los conceptos: la "dispersión" y la "concentración"}

Si bien, como vimos antes, la Ley 26.160 estipula que el relevamiento se efectúe sobre las tierras de OATP, cada provincia impregna su particularidad de acuerdo a las trayectorias de relación entre agencias indígenas, privadas y estatales. Río Negro es la única provincia donde se contempla relevar, además de comunidades, a "pobladores dispersos". Esa diferenciación abre una primera gran esquematización que se plasma en las concepciones sobre el territorio. Tanto por su indefinición, como por su numerosa presencia, el listado de "pobladores dispersos" se presenta como el punto más controversial dentro del Programa de relevamiento. A su vez, problematiza tanto la concepción de comunidad, como la de OATP que maneja el Programa.

Según el uso extendido dentro de las organizaciones mapuche, las comunidades -en los términos vistos en el primer apartado-, ocupan un territorio unificado y contiguo. A diferencia de ellas, los "pobladores dispersos" tendrían un territorio fragmentado e irregular que se correspondería directamente con "pérdida" de la cultura mapuche. A partir de la reflexión crítica de esos supuestos, uno de los principales objetivos de la representación mapuche involucrada en el Programa fue cuestionar la idea de "pérdida cultural" y de "falta de organización" y dar cuenta que las trayectorias no estaban escindidas ni de las experiencias colectivas ni del espacio.

Indagando, por un lado, en la organización "tradicional" mapuche, se comenzó a complejizar el presente de las comunidades. Los mismos participantes del taller pusieron en relieve que, con posterioridad a las campañas militares, las personas se agruparon en un margen estrecho de posibilidades con el fin de ser identificados por el Estado y así sobrevivir. De ellas, solo algunas obtuvieron reconocimientos como grupo. Asimismo, se dio cuenta de la existencia de comunidades ceremoniales que se organizan en torno a los kamarikun [ceremonia anual mapuche] y que no necesariamente viven en un mismo espacio. Por otro lado, hay comunidades de "reciente conformación" o, dicho de otra manera, que han podido ser reconocidas en tiempos contemporáneos y que no mucho 
tiempo atrás eran interpeladas como "pobladores dispersos". Mientras que para terratenientes y corporaciones mediáticas esas comunidades son "advenedizas"15, para los activistas mapuche esas articulaciones son posibles por un proceso de reorganización que revierte paulatinamente la fragmentación social producida por la violencia.

Los planteos dieron cuenta que la revisión de las nociones de "concentrado" y "disperso" implica, fundamentalmente, la historización de los derroteros que siguieron a la finalización de las campañas militares. Asimismo, fue posible introducir en las discusiones las distintas concepciones de "organización social", así como de "usos tradicionales" que el Programa de relevamiento se propone mapear.

Definiendo los usos: entre la fijación y el movimiento

La aparente diferencia entre "comunidades" que parecieran hacer un uso "tradicional" de las que deben esforzarse en demostrar su pertenencia indígena mapuche, también incide en la idea de usos. El énfasis que se le da en el manual del Programa de Relevamiento apunta a definir el uso "en función de la economía de subsistencia que practican las comunidades" (INAI, s/f: 45). Entre esos usos se contemplan el cultivo y la cría de ganado, pero también se incluyen los lugares de culto. EI ETO releva los usos en la etapa de construcción de la narrativa, donde ciertos "objetos" son identificados por sus "atributos" en tanto sitios productivos, religiosos o de residencia. Así, en el manual, se ejemplifican algunos de esos objetos,

\footnotetext{
15 Durante 2009 el diario Río Negro, uno de los principales referentes de la prensa escrita de la Patagonia, incorporó a su agenda informativa los reclamos de las sociedades rurales que representan a estancieros ganaderos. Las publicaciones apuntaban a denunciar lo que consideraban como "usurpaciones" de tierras por parte de comunidades mapuche. Recientemente, el mismo medio publicó un dossier cuya operación mediática consiste en reafirmar la idea de "extranjería" mapuche, justificando así la posición que considera ilegítima e ilegal la demanda territorial indígena (ver http://www.rionegro.com.ar/diario/ investigaciones-de-rio-negro-5650698-9701-nota_ multifoto.aspx).
}

como el "curso de agua", la "zona de residencia", el "camino", la "zona de cultivos" o el "lugar de culto", cuya identificación se establece mediante una serie de preguntas (por ejemplo, ¿cuál es el nombre originario y en castellano?, ¿cuáles son las características principales?, y ¿cuáles son los usos que le da la comunidad?). Los usos previstos en el manual contemplan la movilidad en relación a la subsistencia y a ciertos diacríticos. En los talleres, esas nociones se consideraron en relación a la modificación de pautas que dieron origen a otras configuraciones espaciales, modificando usos:

"[...] mire lo que era mi abuela, Ilegó, pasó por Anükon, ${ }^{16}$ toda esa parte se recorrió. Antiguamente, los mapuches no tenían paradero fijo. Eso siempre me voy a acordar, yo lo alcancé a ver eso también, lo alcancé a vivir porque mi padre y mi madre también... feymu ka amupey ka mapu chulengeyaway tati, pifiñ amutuay tati tiew ta tripay tati [iban a otra parte a andar cazando guanacos, dijo, volvemos allá donde salen] [...]. Pero cuando llegaron los blancos se cortó todo, no hubo más salida, porque antes los animales se volvían solos al rodeo, no precisaba ir a buscarlos y no había campo alambrado, había mojone [sic]. Cada lindero sabía cuál era el lugar de ellos. Los peñi [referencia de un hombre a otro] se decían: 'te encargo el animal, si pasa para allá córremelo pa' acá'. Por eso digo, qué lindo sería estar en esa vida" (T.E., taller con hablantes, 2012. Traducción: Pablo Cañumil).

Los itinerarios por diferentes lugares a partir de prácticas como la caza, convivían con sitios de fijación -como la residencia o el pastoreo- que estaban igualmente delimitados y que eran compartidos y regulados juntos a otros mapuche. La práctica de la movilidad permanente se trunca en décadas recientes con la política de la fijación que es implementada en el norte patagónico desde

\footnotetext{
16 Se refiere a un fütake pillañ wingkul [gran cerro ceremonial] que da origen a la comunidad Füta Anekon y a un pichike pillañ wingkul [cerro ceremonial de menor envergadura]. Ambos dan nombre a dos parajes, Anecón Grande y Anecón Chico, ubicados en el sudoeste de la provincia.
} 
sectores estatales y privados y destinada, especialmente, hacia una porción de la población que englobaba a indígenas, campesinos pobres e inmigrantes chilenos (desvalorizados por su condición de inmigrantes no deseables). Esas políticas apuntaron a desterrar a pobladores indígenas e implementar una forma diferente de ocupación de la tierra a través del terror y la violencia. Para eso se diseñó la creación de cuerpos policiales conocidos como "La Fronteriza" que registran antecedentes particularmente violentos en la zona del noroeste rionegrino (Suárez, 2003; Pérez, 2014).

“El paradero lo tenían, pero ellos iban recorriendo donde era mejor. Pero lo que lo jodió [sic.] en 1931 que vino "La Fronteriza", puso límite, no lo dejó volver [sic.], al contrario, nos quitó campo. Todos tienen cría de animales y ahí fue donde se establecieron, sino seguían" (E.C., taller con hablantes, marzo de 2012).

El recuerdo sobre la modificación de las pautas mapuche de ocupación y uso del espacio está contenido en los relatos que establecen una continuidad entre el "límite" y el "alambre".

"Yo recuerdo que en 1900 y tanto, no había alambre por ninguna parte, pero había gente... y el gobierno entregaba poste, alambre para que alambren y después venían los representante, director, representante [sic.] del gobierno y se lo vendían. Hacían pelear a la gente. Mi padre no dejó alambrar a ninguno de su gente y no alambraron. Después atropellaron los blancos" (D.C., taller con hablantes, marzo de 2012).

Aunque la movilidad es parte constitutiva de la historia mapuche, y también fue una de las consecuencias de la invasión militar a los territorios indígenas, en el Programa de relevamiento tanto técnicos como referentes indígenas venían contemplando solo los recorridos entre sitios productivos. Sin embargo, en el intento por cerrar en una definición términos como lof, territorio tradicional, ocupación tradicional, entre otros, emergieron tantas definiciones como trayectorias colectivas distintas se registran en la memoria social mapuche.
"[...] el lof tampoco define el lugar, porque la gente se va moviendo. Ahora no tienen veranada e invernada, pero hay casos que sí [...]. La gente se movía y mi abuelo era así también. Y eso no es más o menos dañino que quedarse siempre en el mismo lugar. Los trayectos hacia las salinas, por ejemplo, eso se cuenta mucho en nuestra comunidad. Los lugares donde están las pinturas rupestres. Los más jóvenes te dicen 'eso es un palenque' y los viejos te dicen 'no, ese era un lugar estratégico de escondite', donde hay chenque [cementerio]. De un día para otro empezamos a ver las cosas [que] andá a saber de cuánto tiempo están ahí" (B.A., taller sobre conceptos, 2011).

Las persecuciones militares de la "Conquista del Desierto" convirtieron a ciertos lugares en escondites que siguen teniendo capacidad performativa en el presente, tanto a partir de su actualización como "sitio de memoria" como para la definición de los lugares comunitarios. A su vez, estos sitios territorializan pertenencias a partir de trayectorias sociales que se configuran en, y por, determinados espacios y objetos contenidos dentro de ellos. Desde la perspectiva del Programa, resulta difícil mapear los usos que se les dan a los palenques como escondite, y que configuran los sentidos sobre el espacio y los territorializa a partir de otorgarle historicidad a las diferentes prácticas. Los cuestionamientos al tipo de relevamiento propuesto por el Programa hicieron énfasis en aquellos tipos de uso que, aun siendo actuales, no habían sido contemplados por los técnicos del relevamiento por no corresponderse exclusivamente dentro de una economía de subsistencia. Uno de los técnicos no indígenas del ETO exponía respecto al "uso tradicional":

“¿Qué características tiene eso para las comunidades mapuches? Hay casos en los que se plantea que no se hace uso tradicional de acuerdo a lo que otros dicen que debe ser el uso tradicional, por ejemplo, si no hay cultivos o animales... ¿Cómo definirlo para el pueblo mapuche, si no se lo usa como uno esperaría?" (S.G., taller sobre conceptos, 2011).

Si tomamos en cuenta la distinción que plantea Santos (1994) entre verticalidades y 
horizontalidades, la forma en que se expresan los tipos de uso desde la perspectiva mapuche estaría conformando un territorio híbrido formado por redes y no es solo un territorio continuo. Gran parte de las redes territoriales mapuche fueron eliminadas como producto de la entrega de tierras a terceros. Sin embargo, algunas redes territoriales mapuche permanecieron vigentes y disputando la lógica de ocupación de la propiedad privada. Aunque se compruebe el uso itinerante de ciertos lugares que atraviesan lógicas impuestas, esas redes constituyen un desafío a la hora de trazar mapas. Si el ejercicio de poder se basa también en circular y comunicar a través de redes (Raffestin, 1993), restringir o eliminar esas redes es también parte de esa construcción.

Ocupación actual, tradicional y pública: el conflicto territorial en los mapas

El debate en los talleres también versó en torno a las formas en que, desde las instituciones estatales, se concibe la ocupación tradicional indígena. Según los lineamientos detallados en el manual del Programa de Relevamiento, "los aspectos que definen a los Pueblos Indígenas" se encuentran estrictamente demarcados dentro de "deslindes, límites y fronteras territoriales". Esos límites son útiles tanto "para distinguirse de otros, como para organizar y ordenar el uso, posesión, aprovechamiento y/o usufructo de los espacios dentro de un territorio" (INAI, s/f: 27). Esta definición, nos permite pensar en dos aspectos. Por un lado, el uso como perspectiva para definir límites y caracterizaciones hacia "adentro" y, por otro, el aspecto cartográfico como dispositivo de territorialización dentro de las cartografías hegemónicas provinciales y nacionales. Ambos aspectos están íntimamente relacionados a la política estatal de fijación.

Una de las formas de construir, canalizar y disputar poder en el proceso de territorialización son las cartografías. Por medio de ellas, circulan determinados tipos de información con mayor o menor grado de legitimidad en la arena donde se disputan signos y significados proyectados sobre un espacio. En el caso que analizamos, los productos más importantes del relevamiento son los diferentes tipos de cartografías que se elaboran para dar cuenta de la ocupación de cada comunidad. El objetivo final es que el Estado, a través del INAI, cuente con una base de datos acerca de la situación y ubicación de la ocupación territorial de los indígenas relevados en el país para la aplicación de diferentes políticas.

En la definición de territorios tradicionales (ver apartado anterior) la noción de "hitos geográficos" no está caracterizada, aunque se estima que estarían identificados en diferentes tipos de objetos cuyos atributos están definidos por el uso. La enumeración de aquellos elementos que identificarían un territorio tradicional indígena parte de la necesidad de delimitación que expresaría un tipo de jurisdicción indígena ordenada por normas y leyes propias. Esta jurisdicción gobernada por un cacique o "representante" de la comunidad está directamente vinculada a la noción de "tribu", que sigue siendo el modo de organización por excelencia con el cual el Estado ha homogeneizado -y estigmatizado- a los diferentes tipos de organización indígena. A eso se sigue que las "tribus" están concentradas, próximas y ocupando un territorio contiguo.

Respecto de la relación entre jurisdicción y formas de ocupación, transmisión y uso de la tierra, el manual del Programa puntualiza que, al aplicarse desde el Estado una política de propiedad sobre los territorios, "se reconocía lo efectivamente ocupado, es decir, el lugar de las viviendas y zonas de producción, pero no así sus jurisdicciones comunales" que, al haber sido asignadas en propiedad privada, no aseguraron "la permanencia del uso extensivo sobre extensas praderas", obligando a las comunidades "a reducir drásticamente sus tierras y a un uso del suelo de subsistencia precaria" (INAI, s/f: 25). El mismo manual advierte que la "ocupación se manifiesta de manera diferente $y$ no siempre es evidente por el modo cultural de producción", agregando que "los signos de la posesión [...] están marcados de forma indeleble en la memoria histórica de los pueblos indígenas", siendo ella "indisociable de la geografía" y "principal señal de posesión tradicional actual" (INAI, s/f: 24). También recalca que, si bien "las tierras en manos indígenas se consideran como territorios étnicos, sobre la base que ellas son propiedad constituida $[\ldots]$, no se consideran las tierras 
aledañas en posesión de terceros [...] que les fueron enajenadas por variados métodos" (INAI, s/f: 25).

Esa es justamente la cuestión que se presenta como central y la más problemática para los actores involucrados en el Programa -tanto técnicos, como indígenas-. Uno de los cuestionamientos surgidos en los talleres fue que la concepción de OATP establecida por el Programa situaba objetos con atributos dentro de una cartografía previamente trazada -por ejemplo, los mapas catastrales-. Tal delimitación impedía cuestionar la idea de "límite" y "borde". Al avance del latifundio sobre dominios territoriales indígenas se han incorporado, recientemente, inversiones que implican nuevos conflictos por la determinación de los límites de la ocupación indígena (entre ellos, proyectos petroleros, gasoductos y corredores bioceánicos). La pelea por delimitar la jurisdicción indígena se presenta como una de las más fuertes disputas.

Para demarcar los límites y las fronteras de los territorios tradicionales, se consideran dos aspectos: uno "político-territorial" y otro del "espacio cultural". Para definir esos límites se utilizan los datos del Informe Histórico Antropológico y la Narrativa de la comunidad. También el Informe Jurídico se orienta hacia el objetivo de "deslindar y redelimitar el territorio político jurisdiccional" (INAI, s/f: 27). El segundo aspecto, el del espacio cultural, se basa también en estos informes, pero no solo contempla la ocupación actual y pública de la comunidad, sino que toda aquella extensión territorial que la comunidad no detenta. Sin embargo, al momento de historizar la ocupación tradicional de las comunidades, indígenas y técnicos continuaban manteniendo como premisa que lo único objetivable son ciertas prácticas económicas (estableciendo lugares fijos de pastoreo). Asimismo, dentro de las prácticas "culturales" se contaban solo aquellas que implicaban mayor extrañamiento para la vista de los técnicos, como las ceremonias religiosas y los cementerios. Algunas comunidades identificaron sitios y objetos que eran igualmente significativos (como el palenque que vimos anteriormente), pero que por encontrarse dentro de otra "jurisdicción" -la de un tercero privado- no fue relevada dentro de los objetos a mapear. El límite, en ese caso el alambre, se dio por sentado y lo establecía la misma propiedad privada que cuestionaban los integrantes de la comunidad.

Frente a la necesidad planteada por las organizaciones mapuche y los técnicos del ETO de cartografiar de manera diferente, se comenzó a discutir la hegemonía de un tipo de jurisdicción. En algunos casos, territorios relevados como "Territorio en conflicto" cuando en realidad correspondía a territorios de OATP. El problema de concepciones residía en torno a cuán "demostrables" resultaban los despojos. Muchas veces no había documentos judiciales o de reparticiones estatales que verificaran la ocupación con anterioridad a 2006. Sin embargo, la práctica, el uso y el testimonio de los miembros de las comunidades avalaban la permanencia en el lugar. La divergencia planteada por algunos técnicos en torno a qué evidencias posibles "mapear" coloca nuevamente la pregunta por el poder territorializador del Estado que establece qué delimitar y para quiénes.

\section{Palabras finales}

Este trabajo partió de preguntarse sobre qué nociones de territorio, ocupación y uso del espacio redefinen los mapuche en la provincia de Río Negro en el marco de la aplicación de la Ley 26.160. A partir de ese interrogante, fue necesario historizar sobre el proceso de reconocimientos estatales a la ocupación indígena que hubo entre fines de siglo XIX y durante el siglo XX. Asimismo, dimos cuenta del proceso particular de territorialización rionegrina y que se expresa en torno a la categoría de zona o zona-región. Ambos procesos inciden en la distribución de los modos de ocupar el espacio y los lugares sociales entre los mapuche en Río Negro. De esa distribución dan cuenta categorías como la de "poblador disperso" que se presenta como problemática, tanto para los técnicos del ETO como para las organizaciones mapuche. La necesidad de definir categorías, viró la mirada de técnicos y de activistas mapuche hacia la diversidad de colectivos atomizados por políticas de entrega de tierras que determinó movilidades y concepciones de comunidad. Así, se problematizó la noción de "territorio tradicional" en base a los modos de ocupar el espacio. 
También expusimos de qué manera las cartografías evidencian los "desajustes" entre lo que el Estado ha reconocido y los tipos de uso evidenciado por el relevamiento técnico que da cuenta cómo el tránsito entre lugares configuran otras territorialidades. La idea de fijación entra en conflicto con prácticas de movilidad y desplazamiento. La identificación de lugares conectados a partir de recorridos y tránsitos, de concepciones particulares acerca de esos objetos (como los palenques) y de modalidades de fijación (residencia, sitios ceremoniales, cementerios) son parte de la disputa por conseguir que se plasmen en los mapas los modos tradicionales mapuche de usar y ocupar el territorio. Si bien la intención de los técnicos en el Programa es contemplar múltiples escalas, la idea de cartografiar territorios-red como OATP irrumpe en la espacialización basada en la concentración y la fijación que distribuye y estructura movilidades. El movimiento, redefinido en las discusiones, se presentaría así como instrumento analítico y marco de interpretación que tensiona los límites jurisdiccionales que se buscan cartografiar.

A modo de epílogo, es necesario mencionar que al finalizar este trabajo se produjo la sanción del nuevo Código Civil y Comercial argentino ${ }^{17}$, cuya reforma incorporó un artículo que reconoce la propiedad comunitaria indígena ${ }^{18}$. Dado que el Programa de Relevamiento Territorial se plantea como la antesala de la titularización de las tierras indígenas, esta reforma actualiza el debate en torno a los reconocimientos territoriales. Numerosos sectores -tanto los vinculados a la defensa de derechos indígenas como a los derechos civiles y constitucionales- han reprochado que no se hizo efectivo el cum-

17 El texto del Nuevo Código Civil y Comercial argentino entró en vigencia el 1 de agosto de 2015.

${ }^{18}$ El artículo se incluye en el Capítulo IV sobre "Derechos y bienes" y dice: Derechos de las comunidades indígenas. Las comunidades indígenas reconocidas tienen derecho a la posesión y propiedad comunitaria de las tierras que tradicionalmente ocupan y de aquellas otras aptas y suficientes para el desarrollo humano según lo establezca la ley, de conformidad con lo dispuesto por el artículo 75 inciso 17 de la Constitución Nacional (Artículo 18). plimiento del derecho de consulta previa, libre e informada de los indígenas al que está obligado el Estado argentino. Según esos sectores, ante la falta de concreción del proceso de consulta del anteproyecto, el derecho de propiedad comunitaria indígena no ha podido ser incluido dentro del Código reformado como un derecho real autónomo -con sus propios articulados que lo harían directamente aplicable-, sino que está supeditado a la sanción de una ley especial que lo caracterice, configure y regule.

Atento a esa regulación, la controversia mayor gira en torno a la homologación de la noción de "propiedad" y "posesión" del derecho privado a las formas de ocupar los territorios indígenas. En el derecho civil ordinario, las posesiones pueden ser legítimas o no, pero siempre que el estado reconozca "propiedad" estaría salvaguardando un derecho sobre un bien delimitado del cual el propietario (persona física o jurídica) puede disponer, usar y controlar. El cuerpo legislativo indígena entiende que la "posesión" otorga de por sí el derecho a la "propiedad", por lo tanto, no habría que legislar una ley que jerarquice tipos de posesión y otra que garantice propiedad. Y dado que el derecho a la "propiedad" no solo atañe a la producción, la preocupación gira en torno a que se omitan redes de movilidad, territorios-red y formas de ocupación compartidas imponiendo, nuevamente, una configuración unívoca de territorio sobre las territorializaciones indígenas. Es decir, oculte las formas de producción del espacio que el mismo Programa de relevamiento puso en evidencia a partir de la reflexión de los términos de su aplicación.

Es un hecho que estas demandas convertidas en políticas públicas vienen, por primera vez, a reparar sociedades sometidas por el Estado argentino. También es cierto que las contradicciones que surgen son insoslayables, puesto que tensionan la génesis misma de producción de la matriz Estado-naciónterritorio y de subjetividades. En ese sentido, el debate sobre los reconocimientos de los territorios indígenas involucra al conjunto de la sociedad. 


\section{Referencias bibliográficas}

AA.VV.; REY, H. y VIDAL, L. (compiladores). Historia de Río Negro. Viedma: Gobierno de Río Negro, 1974.

BECHIS, M. Instrumentos para el estudio de las relaciones interétnicas en el período formativo y de consolidación de los estados nacionales. En: HIDALGO, C. y TAMAGNO, L. (compiladores). Etnicidad e Identidad. Buenos Aires: CEAL, [1984] 1992, p. 82-120.

BENEDETTI, A. Los usos de la categoría región en el pensamiento geográfico argentino. Scripta Nova. Revista Electrónica de Geografía y Ciencias sociales, 2009, Vol. XII, N²86. Disponible en Internet: http://www.ub.edu/geocrit/sn/sn-286.htm

BRIONES, C. y CARRASCO, M. Pacta sunt Servanda. Capitulaciones, convenios y tratados con indígenas en Pampa y Patagonia (Argentina 1742-1878). Buenos Aires: IWGIA, 2000.

BRIONES, C. y DELRÍO, W. Patria sí, Colonias también. Estrategias diferenciales de radicación de indígenas en Pampa y $\mathrm{Pa}$ tagonia (1885-1900). En: TERUEL, A.; LACARRIEU, M. y JEREZ, O. (compiladores). Fronteras, ciudades y Estados, Tomo I. Córdoba: Alción Editora, 2002, p. 45-78.

BRIONES, C. \& DELRÍO, W. The 'Conquest of the Desert' as trope and enactment of Argentina's Manifest Destiny. In: MAYBURYLEWIS, D.; MACDONALD, T. \& MAYBURYLEWIS, B. (editors). Manifest Destinies and Indigenous Peoples. Cambridge: Harvard UP, 2009, p. 51-84.

CAÑUQUEO, L. 'Tramitando' comunidad indígena en Río Negro. Diálogos entre activismo, políticas de reconocimiento y cogestión. Identidades. Revista del Instituto de Estudios Sociales y Políticos de la Patagonia, 2015, Año 5, Nº 8, p. 62-80.

CAÑUQUEO, L.; KROPFF, L.; RODRÍGUEZ, M. y VIVALDI, A. Tierras, indios y zonas en la provincia de Río Negro. En: BRIONES, C. (editor). Cartografías argentinas. Políticas indigenistas y formaciones provinciales de Alteridad. Buenos Aires: Antropofagia, 2005, p. 119-149.
CASA DE LA PROVINCIA DE RÍO NEGRO. A.I.G.C.R.N. Informe, 1994.

CONSEJO DE DESARRROLLO DE COMUNIDADES INDÍGENAS (Co.De.C.I.). Personería Jurídica de las Comunidades Indígenas. Convenio 156/01, 2006.

COORDINACIÓN DE ORGANIZACIONES MAPUCHE TAYIÑ KIÑEGETUAM -Para volver a ser uno-. Estatuto Autónomo del Lof Kallfvkura. Buenos Aires: Mimeo, 1995.

DELRÍO, W. Memorias de expropiación. Sometimiento e incorporación indígena en la Patagonia (1872-1943). Bernal: Editorial de la Universidad Nacional de Quilmes, 2005.

DELRÍO, W. y PÉREZ, P. Territorializaciones y prácticas estatales: percepciones del espacio social luego de la Conquista del Desierto. En: NAVARRO FLORIA, P. y DELRÍO, W. (compiladores). Cultura y Espacio: Araucanía-Norpatagonia. Bariloche: UNRN-IIDyPCa, 2011, p. 237-254.

Delrío, W.; PALMA, C. y PÉREZ, P. Marco histórico. Las (des)territorializaciones estatales en lo que hoy es la Provincia de Río Negro. En: CAÑUQUEO, L.; KROPFF, L.; PÉREZ, P. y WALLACE, J. (coordinadoras). Informe Preliminar 2014, Comisión Investigadora para la Transferencia de Tierras Rurales en el ámbito de la Provincia de Río Negro (Ley 4744). Viedma: Legislatura, 2014. Disponible en Internet:

http://www.legisrn.gov.ar/Irn/wp-content/ uploads/2015/03/inftierras.pdf

DIRECCIÓN GENERAL DE TIERRAS DE RÍO NEGRO. Listado de reservas aborígenes. 2000.

GOBIERNO DE LA PROVINCIA DE RÍO NEGRO. Reseña, Geografía. 2014. Disponible en Internet: http://www.rionegro.gov. $\mathrm{ar} /$ typeID=0\&pagina=resena

GROSSBERG, L. We gotta get out of this place. Popular Conservatism and Postmodern culture. Nueva York \& Londres: Routledge, 1992.

GUIÑAZÚ, S. Agencia y resistencia indígena. Un análisis sobre el relevamiento 
territorial de comunidades indígenas en la provincia de Río Negro. En: Actas del Tercer Congreso Latinoamericano de Antropología ALA 2012, 2012.

HAESBAERT, R. O mito da desterritorializÇão: do "fim dos territórios" á multiterritorialidade. Rio de Janeiro: Bertrand Brasil, 2007.

INSTITUTO NACIONAL DE ASUNTOS INDÍGENAS (INAI). Manual del Programa Nacional Relevamiento Territorial de Comunidades Indígenas. Ley Nacional N²6.160. S/f.

INSTITUTO NACIONAL DE ASUNTOS INDÍGENAS (INAI). Propuesta Cartográfica para la Carpeta Técnica. Área de Georreferenciamiento, 2011.

LENTON, D. De centauros a protegidos. La construcción del sujeto de la política indigenista Argentina desde los debates parlamentarios (1880-1970). Buenos Aires: Mimeo, tesis doctoral, Universidad de Buenos Aires, 2005.

MASES, E. Estado y cuestión indígena. EI destino final de los indios sometidos en el sur del territorio (1878-1910). Buenos Aires: Prometeo Libros, 2002.

NAGY, M. y PAPAZIAN, A. De la Isla como Campo. Prácticas de disciplinamiento indígena en la Isla Martín García hacia fines s. XIX. En: Actas de las XII Jornadas Interescuelas-Departamentos de Historia. San Carlos de Bariloche: Universidad Nacional del Comahue, 2009.

NAVARRO FLORIA, P. La 'República posible' conquista el 'Desierto'. La mirada del reformismo liberal sobre los territorios del sur argentino. En: Paisajes del Progreso. La resignificación de la Patagonia Norte, 1880 -1916. Neuquén: UNCo, 2007.

PÉREZ, P. Estado, indígenas y violencia. La producción del espacio social en los márgenes del estado argentino. Patagonia central 1880-1940. Buenos Aires: Mimeo, tesis doctoral, Universidad de Buenos Aires, 2014.

QUINTERO, S. Geografía regional en la Argentina. Imagen y valorización del territorio durante la primera mitad del siglo XX. Scripta Nova. Revista Electrónica de Geografía y Ciencias sociales, 2002, Vol. VI, $\mathrm{N}^{\circ}$ 127. Disponible en Internet: http://www.ub.es/geocrit/sn/sn-127.htm

RADOVICH, J.C. y BALAZOTE, A. Transiciones y Fronteras Agropecuarias en Norpatagonia. En: TRINCHERO, H. (editor). Producción Doméstica y Capital. Estudios desde la Antropología Económica. Buenos Aires: Biblos, 1995.

RAFFESTIN, C. Por uma geografia do poder. São Paulo: Atica, 1993 (1980).

RED DE INVESTIGADORES SOBRE GENOCIDIO Y POLÍTICA INDÍGENA EN ARGENTINA (RIG). Del silencio al ruido en la Historia. Prácticas genocidas y Pueblos Originarios en Argentina. En: Actas III Seminario Internacional Políticas de la Memoria. Buenos Aires, 2010. Disponible en Internet:

http://www.mapaeducativo.edu.ar/pueblos_indigenas/images/2_\%20silencio_ruido. pdf

SACK, R. Human territoriality. Its theory and history. Cambridge: Cambridge University Press, 1986.

SALOMON TARQUINI, C. Largas noches en La Pampa. Itinerarios y resistencias de la población indígena (1876-1976). Buenos Aires: Prometeo, 2010.

SANTOS, M. El retorno del territorio. En: SANTOS, M.; SOUZA, M. \& SILVEIRA, M. (organizadores). Territorio. Globalizaçâo e Fragmentaçâo. São Paulo: Hucitec, 1994.

SUÁREZ, G. La Policía en la Región Andina Rionegrina 1880-1920. Revista Pilquen, 2003, No 5 .

UNIVERSIDAD NACIONAL DEL COMAHUE Y ASAMBLEA POR LOS DERECHOS HUMANOS. Defensa y Reivindicación de Tierras Indígenas. Proyecto Especial de Investigación y Extensión. Neuquén: UNC-APDH, 1996, p. 208-213.

ZUSMAN, P. y MINVIELLE, S. Sociedades geográficas y delimitación del territorio en la construcción del Estado-nación argentino. En: Actas del V Encuentro de Geógrafos de América Latina. La Habana, 1995. 